\title{
Tandem Mass Tag
}

National Cancer Institute

\section{Source}

National Cancer Institute. Tandem Mass Tag. NCI Thesaurus. Code C161866.

A group of amine-reactive reagents used as tags for isobaric mass labeling that are comprised of a mass reporter region (M), a cleavable linker region (F), a mass normalization region (N) and a protein reactive group (R). Tandem mass tags (TMT) are added to peptides following sample collection, protein purification and protein digestion. These tags are identical in chemical composition but isotope substitutions in the $\mathrm{M}$ and $\mathrm{N}$ regions allow these regions to have different molecular masses. The number of isotope substitutions is equal to the number of distinct samples that can be tagged and assayed. 